\title{
Conceptual and Practical Issues in the Pharmacological Treatment of Brain Injury
}

\author{
Donald G. Stein, Marylou M. Glasier and Stuart W. Hoffman
}

Brain Research Laboratory, Institute of Animal Behavior, Rutgers University, Newark, NJ 07102, USA

\begin{abstract}
It is only within the last ten years that research on treatment for central nervous system (CNS) recovery after injury has become more focused on the complexities involved in promoting recovery from brain injury when the CNS is viewed as an integrated and dynamic system. There have been major advances in research in recovery over the last decade, including new information on the mechanics and genetics of metabolism and chemical activity, the definition of excitotoxic effects and the discovery that the brain itself secretes complex proteins, peptides and hormones which are capable of directly stimulating the repair of damaged neurons or blocking some of the degenerative processes caused by the injury cascade. Many of these agents, plus other nontoxic naturally occurring substances, are being tested as treatment for brain injury. Further work is needed to determine appropriate combinations of treatments and optimum times of administration with respect to the time course of the CNS disorder. In order to understand the mechanisms that mediate traumatic brain injury and repair, there must be a merging of findings from neurochemical studies with data from intensive behavioral testing.
\end{abstract}

\section{INTRODUCTION: CURRENT PERSPECTIVES}

This review begins with the assumption that agents which promote functional recovery from traumatic brain injury produce effects not only at the site of the injury, but throughout the central

This article is an adaptation of a chapter to appear in Christensen, A.-L. \& Uzzell, B.P. "Neuropyschological Rehabilitation", L. Erlbaum Publishers, Englewood (1993), with permission. nervous system. A corollary of that view is that symptoms, syndromes and the behavioral recovery following brain injury, depend very much upon the context in which the injury occurred and not just on the site of the injury itself. By "context", we mean factors such as: age and prior health status of the subject at the time of injury, gender of the patient, hormonal conditions and indeed, even the environmental conditions under which the subject is raised. All such factors can play a role in determining the success or failure of treatments designed to promote recovery. This contextual issue has gained in importance as more sophisticated assessment and evaluation techniques permit access to increasingly better, non-invasive views of the functional and metabolic activity in the living brain. For example, progress has been made in brain imaging techniques that would seem to permit one to "localize the injury" and by extension, assign the nature of the deficit to the damaged tissue itself. Despite these new methods, we would reiterate that environmental and organismic variables must be taken into account in deciding upon the prognosis for recovery as well as for the course of rehabilitation therapy provided for the patient.

Although this focus on a more holistic perspective can be seen as a point more appropriate for academic discussion than clinical practice, it is an important theoretical issue not only for academicians, but also for those directly involved in treatment of brain injured patients. The issue of plasticity lies at the heart of thinking about how the nervous system is organized, how "plastic" responses may be engendered after injury, and how appropriate treatment strategies may be developed and employed.

It is only within the last ten years that some neurologists and neuropsychologists involved with head injury have become more focused on the complexities involved in promoting recovery from 
brain injury when the CNS is viewed as an integrated and dynamic system. Prior to this, the main task in dealing with head trauma was first to stabilize the patient and then to diagnose and, in the process, localize the deficits. In general, follow-up therapy was left to rehabilitation specialists and physiatrists whose basic task was to enable the patient to compensate for and cope with his/her disability rather than to promote functional recovery per se. Thus, while a change in attitude about CNS organization is slowly taking place, much emphasis in neuroscience is still on identifying pathways, chemical assays of specific brain regions and the demonstration and perfection of exquisite, hodological techniques. Given this molecular perspective, it is not surprising that a widely read textbook in medical neuroscience /32: p. 15/ states that:

"...all behavior, including higher mental functioning (affective as well as cognitive), can be localized to specific regions or constellations of regions within the brain.

Descriptive neuroanatomy provides us with a

functional guide to local sites within the brain that correspond to specific behaviors." (our underline)

The focus on molecular techniques and upon ever smaller units of function and brain cartography which characterize current thinking about the brain overlooks the fact that it is a patient who has brain damage and not just a region of the brain itself. Clearly, the mechanistic-reductionist perspective offers small hope to patients and provides little basis for formation and testing of hypotheses about the diverse mechanisms underlying functional recovery and CNS repair.

Conceptual development, requiring detailed behavioral assessment, the hallmark of experimental neuropsychology, has given way to an emphasis on map-making and highly localized molecular structure and function. Indeed, the state-of-the-art of behavioral work associated with treatment for recovery from injury was noted by the authors of a best-selling neuropharmacology text book /16: p.4/, who state that:

"... at the molecular level, an explanation of the action of a drug is often possible, at the cellular level, an explanation is sometimes possible, but at a behavioral level, our ignorance is abysmal."

Current imaging techniques lend themselves to focusing on the tree instead of the forest and emphasize localization of various activities in response to injury rather than a more systemic change occurring throughout the brain as it undergoes the process of reorganization and repair. In metabolic studies, investigators often focus only upon the most intense alterations observed during a given behavior or after an injury. They may ignore the overall pattern and interplay of less intense changes that occur both in the affected hemisphere as well as on the side contralateral to the injury itself. Several recent positron emission tomography (PET) studies of regional cerebral blood flow in patients recovering from stroke $/ 14,62 /$ demonstrate significantly different patterns of activation from those of normal subjects. Importantly, the patterns are shown to be evoked in numerous brain structures involving the whole brain, not just in a few structures to which the deficit might be thought to be "localized".

The elucidation of the mechanisms underlying traumatic brain injury and repair will come from a merging of the findings of molecular biology and neurochemistry concerning alterations in the whole brain with data from intensive behavioral testing, in both human and animal models. In order to understand the subtleties of CNS mechanism and repair, we will need to look carefully at molecular and "localized" findings in conjunction with concomitant distal alterations, and, importantly, we must evaluate these findings in light of their observed effects on multiple standardized behavioral tasks.

\section{ADVANCES IN PHARMACOLOGICAL APPLICATIONS TO BRAIN INJURY}

There have been major advances in research on recovery from brain damage over the last decade. Although few, if any, specific pharmacologic treatments for brain injuries are yet on the market, we how have a much broader understanding of the mechanics and genetics of metabolism and chemical activity in neurons and glial cells. This new information has led to a burst of pre-clinical 
research activity to develop new substances designed to treat brain injury. In fact, in the past five years there has been a dramatic increase in the number of new biotechnology companies whose specific purpose is to develop new drugs for treating brain injury.

Only a short time ago most research on the pharmacology of CNS plasticity was directed to the study of describing how neurons regulate the release and metabolism of neurotransmitters, whose loss or return was the sine qua non for restitution of function. More recent efforts in this field now stress the discovery and characterization of new agents that modulate both neuronal and glial activity under normal and disrupted conditions. Much more emphasis is being placed on the discovery of receptors on both neurons and glial cells and their interdependence in neurotransmitter and neuropeptide release $/ 6,56,38 /$, in responses which can influence how the nervous system adapts to environmental conditions and to trauma.

With respect to the development of a specific pharmacology of recovery from brain damage over the last decade, we believe that there were several fundamentally important areas of research that have had an impact. First, it was confirmed that amino acids involved in CNS metabolism also might serve as neurotransmitters in their own right. In fact, Cooper, Bloom and Roth /16: p. 124/ state that:

"...from a quantitative standpoint (i.e. amounts present in the brain), the amino acids are probably the major neurotransmitters in the mammalian CNS, while the better-known transmitters (acetylcholine, dopamine, etc.) probably account for transmission at only a small percentage of central synaptic sites."

Investigators soon found that the amino acids are not just important for regulation and control of neurotransmission under normal conditions. In a second major research development, it was determined that traumatic brain injury often results in the excessive release of excitatory amino acids such as glutamate. The term 'excessive' is used because, in higher amounts, the same substances required for neural transmission become "toxic" and cause neural death $/ 43,21 /$. The secondary effects of injury may actually be more responsible for some of the behavioral deficits accompanying the trauma than the initial trauma itself. In particular, stroke, ischemia or direct injury to the brain produces a "glutamate cascade" culminating in an excess of calcium ions entering into vulnerable neurons and destroying them (for details of the process, see the excellent review of Zivin and Choi /67/).

Once the pathways for the excitotoxic effects of amino acid neurotransmitters had been determined at the beginning of the decade, it then became feasible to develop specific compounds which could be used to antagonize and block the excitotoxic cascade of events leading to cell death and thus possibly prevent the loss of behavioral functions associated with the damage. For example, there are now agents available which block (antagonize) neuronal glutamate receptors and thus prevent calcium ion toxicity $7,40,60 /$. The effects of these drugs are to reduce the production of free radical peroxidation, cerebral edema and the resultant necrosis of brain tissue and to attenuate behavioral impairments.

Blocking some of the secondary destructive effects of ions and their toxic by-products, such as free radicals, promises to be a major step in the treatment of brain injury /39/. By quenching the chain reactions initiated by these toxic compounds, CNS protection can be conferred at many different levels. Thus, the hope is to limit the chemical reactions that lead to the spread of secondary injury The sites of free radical attack occur mainly in the lipid membranes of vascular endothelial cells, glia, and neurons, disrupting their structure and function. In the case of the endothelial cells, their disruption leads to the breakdown of the blood-brain barrier (BBB), allowing many other generators of free radicals (such as iron, excitatory amino acids, and clotting factors) to enter the brain, causing edema and further tissue destruction. The disruption of the BBB can also facilitate exposure of the brain to blood macrophages and subsequent autoimmune phenomena or non-specific injury. Macrophages possess enzymes in their membranes that produce highly reactive free radicals which can severely damage cell membrane structure. Disruption of neuronal function can be caused by demyelination of axons as well as alterations of membrane fluidity affecting receptors and metabolic enzymes.

In order to block some of these destructive events, our laboratory has studied the effects of alpha tocopherol (vitamin E) on behavioral and 
anatomical recovery following aspiration injury to the frontal cortex in rats. Our results /54/ show that direct application of alpha tocopherol to the wound cavity produces both an increased rate of recovery on a learning task and sparing of neuronal tissue, i.e. higher neuronal counts, smaller ventricle size, and reduced gliosis. In another study by Clifton and coworkers $/ 15 /$, the systemic administration of an alpha tocopherol derivative had significant protective effects when injected either before or after a fluid percussion injury of the cortex in rats. This derivative significantly reduced mortality rate and increased the rate of motor recovery. These two studies demonstrate the ability of vitamin E (as alpha tocopherol or a derivative) to alleviate deficits following traumatic insult to the brain. Walsh also reports similar effects with vitamin $E$ in this symposium. The advantages of working with this substance are that it is easily available, inexpensive and, as far as is known, safe to use.

Another substance that is of plant origin and that has produced beneficial results in both clinical and experimental studies is EGb 761, an extract of the tree Ginkgo biloba. This substance consists of many different compounds called ginkgolides that have antioxidant properties and can inhibit the actions of substances that adversely affect the permeability of the blood-brain barrier $/ 9,42 /$. In our laboratory we have found that treatment with EBb 761 in rats given bilateral frontal cortex aspirations produced significant behavioral improvements on a spatial learning task /2/. Rats given EGb 761 made fewer errors and perseverated less frequently to the incorrect side of a T-maze than their lesion-only counterparts and they also showed more normal exploration behavior in an open-field maze. Anatomical analyses revealed that the treatment with EGb 761 reduced ventricular size, suggesting that EGb 761 prevented the development of cerebral edema. Recently, Brailowsky and coworkers /8/ reported similar effects of EGb 761 in ameliorating the effects of cortical hemiplegia in rats with either motor cortex aspiration lesions or cortical depression produced by injection of gamma-aminobutyric acid (a neurotransmitter) into the brain. In the experiments by Brailowsky and coworkers, both types of "injury" produced shortterm deficits in motor behavior and in both injury models, chronic EGb 761 administration reduced the duration of the behavioral deficits, although the effects of the treatments were more clearly seen after the mechanical injury. Although this line of research is still quite new, it does demonstrate that recovery from traumatic brain injury can be facilitated by administration of relatively benign, naturally occurring substances that pose little threat to the organism.

Concomitant with increased understanding of the normal and post-injury effects of amino acid neurotransmitters, with resultant possibilities for pharmacological intervention, a third major research step occurred which had an impact on the field of pharmacology of recovery from brain damage. The discovery was made that, in response to damage, the brain itself secretes complex proteins, peptides and hormones which are capable of directly stimulating the repair of damaged neurons $/ 5,17,36 /$ or blocking some of the degenerative processes caused by the injury cascade. Substances which stimulate new neuronal growth and/or help to restore damaged membranes are called "neurotrophic agents". When trophic substances are extracted from the brain and placed into culture dishes containing neurons, they keep the cells from dying and actually promote growth of new processes. In vivo, trophic factors may serve to guide regenerating or sprouting terminals to their appropriate target areas in the brain $14,30,35 /$ Trophic factors appear to have their highest concentrations at or near sites of injury and they reach their peak about one week post-injury, thereafter declining in concentration and activity /17/. Research in the area of trophic factors has produced increased understanding of endogenous mechanisms of recovery, and stimulated interest in pharmacological applications of trophic factors after brain damage.

Some researchers have argued that injuryinduced activation of specific glial cells is of primary importance in the production of neurotrophic agents after damage to the CNS /28/. This hypothesis has resulted in consideration of the "beneficial" role of glia in promoting brain injury repair and functional recovery. While the eventual formation of a glial scar is thought to be detrimental to recovery, initial effects may be beneficial /63/. One suggested mechanism for a positive effect is through injuryinduced activation of astrocytic glia cells, with 
subsequent expression and production of nerve growth factor (NGF), which promotes cholinergic sprouting responses $/ 22,28 /$.

The discovery of endogenous, brain-derived, trophic factors which appear to affect neural growth and viability has led to the premise that some degenerative disorders such as Alzheimer's disease (AD) might be treatable with specific factors which selectively affect neurons known to figure importantly in systems which become dysfunctional. For example, it has been proposed that treatment with NGF might serve to alleviate a basal forebrain cholinergic deficit which may underlie the loss of cognitive function seen in $\mathrm{AD} / 30,44 /$. The potential for therapeutic use of these proteins has encouraged a number of pharmaceutical and biotechnology companies to find ways of synthesizing trophic factors or genetically engineering cells that can be grown and modified in culture and are capable of producing commercial quantities of substances which might be needed by an injured brain. Altered cells could replace not only trophic factors, but also neurotransmitters or hormones, which could then be provided to patients on a regular basis $/ 10,13,27 /$. For example, recent intracerebral application of genetically modified fibroblast cells expressing NGF $146 /$ prevented degeneration in $92 \%$ of cholinergic neurons subjected to fimbria fornix lesion

However, we must emphasize that there are grounds for caution and especially for further research in animals before treatments can be applied to humans. Pressure from special interest groups and seriously ill patients who (understandably) demand rapid application before all the facts are known has led to clinical trials before careful assessment of the long-term effects of treatments has been determined in the laboratory. A good example of this approach is the attempt to provide intracerebral injections of NGF directly to patients with Alzheimer's disease. To date, there is no effective way to arrest the cognitive deterioration of these patients. It has been proposed that treatment with NGF might serve to alleviate a basal forebrain cholinergic deficit which may underlie the loss of cognitive function seen in $\mathrm{AD} / 30 \%$. However, an alternative hypothesis concerning the etiology of $\mathrm{AD}$ has been proposed /12/, which suggests that $\mathrm{AD}$ may be initiated by changes in regulatory mechanisms which are responsible for sequential expression of cytoskeletal protein in neurons normally exhibiting structural plasticity. In this hypothesis, certain proteins providing cytoskeletal stabilization are negatively affected, while normally labile proteins remain active. The result of this process is postulated to be a cascade of neural abnormalities, reactive gliosis, and eventual neural degeneration. Thus the putative breakdown in plasticity components and loss of effectiveness of stable cytoskeletal proteins leads to the occurrence of neurofibrillary plaques and tangles in $\mathrm{AD}$ brains, which are associated with resultant cognitive loss. From this perspective, NGF therapy could exacerbate the abnormal growth, and drugs that block NGF synthesis or NGF receptors would be more beneficial in the early stages of $\mathrm{AD}$. These ideas can be taken to suggest that treatments entirely appropriate for one type of injury, such as trauma, or at one stage of development (e.g. young adults), might be completely contraindicated for treatment of other diseases, such as degenerative disorders, or under other conditions (e.g. aged subjects).

\section{STUDIES OF SYSTEMIC ADMINISTRATION OF SUBSTANCES WITH NEUROTROPHIC EFFECTS}

Despite the clear need for caution in extrapolating from pre-clinical studies to the human patient, there are several promising lines of research on the use of trophic factors to promote functional recovery from a variety of traumatic brain injuries. For example, in our laboratory, we have taken the approach of identifying and employing experimental substances which: (a) are effective in the early stages of the injury process; (b) are naturally occurring substances which do not appear to have toxic side effects - even at relatively high doses; (c) can pass the blood-brain barrier, and thus can be repeatedly administered systemically rather than intracerebrally, and (d) have identifiable physiological or histological/anatomical correlates that can be measured and quantified.

In addition to the use of alpha tocopherol and EGb 761 , we have also used a synthetic portion of the peptide hormone adrenocorticotropin (ACTH) as treatment for brain injury. ACTH plays a role in stimulating the adrenal gland to produce 
corticosteroids which, in turn, affect vital functions such as energy metabolism, fluid regulation, and response to stress. ACTH fragments have also been used to enhance cognition and reverse deficits after brain damage $/ 18,65,66 /$. At the physiological level, Richter-Landsburg, Bruns and Flohr /45/ have shown that ACTH fragments promote neurite growth in vitro. It is possible that a similar compound might also protect neurons that would ordinarily die as a consequence of frontal cortex lesions. Further, Strand et al. $155 /$ found that different ACTH analogs had the ability to facilitate the regeneration of peripheral nerves, offering the possibility that these compounds could initiate repair in the damaged CNS. We reasoned that such protection would also result in behavioral recovery of a spatial learning task that is severely impaired after frontal cortex injury. In our experiments, we used BIM-22015 (which is a structural analog of $\mathrm{ACTH}_{4-10}$ ), injected subcutaneously. Our research indicates that BIM-22015 increased the rate of behavioral recovery on a spatial learning task, and the improved performance was accompanied by the sparing of cholinergic neurons in the nucleus basalis magnocellularis /1/. Positive behavioral effects of other ACTH analogs have also been demonstrated by Wolterink et al. $/ 65,66 /$ after chemical lesions to the nucleus accumbens. Their results indicated that the behavioral recovery was not a function of increased activity in the dopaminergic system, but rather of the increased sensitivity of dopamine receptors, which increased the efficiency of the remaining synapses. Recently, Goldman et al. /29/ have reported that their analog $\mathrm{GMM}_{2}$ increased cerebral blood flow and decreased vascular permeability, thus decreasing intracranial pressure after closed head injury in rats. It should be said, however, that all these studies support a role for ACTH analogs in the treatment of head injury, but as in the case of vitamin $E$, the beneficial effects of ACTH analog therapy were more pronounced when the treatment was given soon after the injury.

Our laboratory has also utilized ganglioside GM1, an endogenous glycolipid, in treatment for several types of brain injury. Systemic injections of gangliosides to rats with lesions of the caudate nucleus resulted in a significant reduction of impairment in a battery of behavioral tests designed to reveal the deficits shown by untreated rats with this injury 148/. Anatomical analysis of these subjects revealed early enhancement of neuronal reorganization with treatment $/ 49 /$, a finding similar to the results of GM1 treatment after nigrostriatal lesion $/ 47 /$, where reduction of neuronal degeneration was seen. Systemic administration of GM1 has been shown to ameliorate behavioral deficits after discrete lesion of a diverse number of brain regions $/ 20,52,58,61 /$. In an exciting recent finding, GM1 treatment was given to non-human primates with MPTP-induced parkinsonian syndrome (PS) $/ 53 /$. Not only were dopaminergic levels significantly increased over untreated animals, but also the acute motor problems characterizing PS were ameliorated.

Although understanding of the mechanism of gangliosides' action in normal and in injured tissue is not yet complete, they have been implicated in a number of roles. A partial listing includes modulation of neural regeneration $/ 24,49 /$, possible inhibition of lipid peroxidation $/ 57 /$, membrane stabilization $/ 23,34 /$ and protection of ion pumps and channels found in the cell membrane (for reviews, see $/ 33,52 /$ ). Additionally, current research is exploring a possible involvement of gangliosides in modulation of the effects of endogenous growth factors, such as NGF or epidermal growth factor (EGF) $/ 11,19,52 /$.

\section{ADDITIONAL FACTORS FOR CONSIDERATION}

Because the injury cascade takes place over time and always in the context of the organism's environment, health status and individual learning and emotional history, these variables, in addition to pharmacologic treatment, will play an important role in determining the success or failure of any medical or psychological therapy. It is also becoming increasingly clear that gender may be a significant contributing factor to the processes of cerebral plasticity and any concomitant recovery that can occur in response to brain damage. Gender considerations may also be important in determining the appropriate course of pharmacological therapy for brain damage because the response to drughormone interactions may be very different for males and females or for pre- or post-menopausal females. There are virtually no clinical studies in this 
area, although gender-related differences in response to injury have been shown $/ 37,59 /$ and a relationship between the hormonal status of females at the time of brain injury and the severity of the deficit has been demonstrated $/ 3 /$.

As researchers have learned more about the complexity of the injury-recovery cycle, awareness has been growing of the injury continuum. Especially in CNS injury, an initial insult has not only immediate consequences, but also results in differing morphological and chemical alterations at later stages after injury. Researchers have thus begun to focus on the different stages of the injury process to determine which specific agents might be most effective in blocking neuronal loss and functional impairments and when they should be administered. As mentioned earlier, a substance indicated for treatment in an early stage of the injury process might be ineffective, or actually counterproductive, at a later stage. For example, the potential for survival of striatal transplants into damaged cortical tissue coincides with the period of peak, endogenous trophic factor expression /41/. Recent research with diazepam also stresses the importance of matching administration of treatment to the stage of injury. When diazepam (a GABAergic agonist) was given to rats for several weeks after specific brain injuries, neural degeneration was markedly enhanced and no behavioral recovery could be observed at any time during the testing period, whereas animals not given diazepam were able to show normal recovery within a week after injury $/ 50,51 /$. Importantly, continued administration of diazepam for three weeks, begun immediately after injury, prevented behavioral recovery for three months (the length of the experiment), although the treatment had been discontinued $/ 51 /$. It is quite possible that diazepam begun later in the continuum of the injury would have a different effect. It is worthwhile noting that diazepam or its related compounds are often given to patients with stroke or CNS trauma, immediately after injury, in order to reduce post-injury agitation and help to "stabilize" them. Therefore, we must consider that proper treatments require more complex tailoring to the individual needs of the subject. Not only the type of injury, but also its projected time course, subject-specific variables and the pharmacological consequences of multiple, successive CNS alterations must be considered.

\section{CONCLUSIONS}

\section{Defining recovery}

Although we have learned a great deal about the cascade of events and processes that we now call "brain injury", and although we have made great strides in developing new pharmacological agents to modify and control these events, there are still considerable gaps in our knowledge of functional recovery. While much has been written about functional recovery, workers in this field still do not have available a clear and precise definition of what is meant by the term itself. As the time course of functional recovery may be very long, or the functional recovery may be incomplete or result in different behaviors than in the pre-morbid state, who should define recovery and what criteria should be used? Physicians, social workers, the families of patients, insurers, and employers will all have their own standards for recovery, based on different needs. In deciding the criteria for adequate functional recovery, optimum medical practice may be overshadowed by economic, political and social considerations.

\section{Defining the injury}

As we noted above, there is a complex series of events that occurs following brain injury. However, the nature of these events may differ in a variety of ways from one type of injury to another. For example, some injuries, like contusions, may cause extensive disruption of the blood-brain barrier (e.g. closed head injury) and may leave the brain open to immunological attack. This immunological response can result in increased edema, demyelination, and neuronal death. In those injuries that leave the BBB more-or-less intact, as is the case with excitotoxic lesions, there may be a cascade that is less diffuse and extensive, consequently producing a more localized injury requiring less complex or extended treatment. The type of injury sustained will determine what specific pharmacologic agents should be used, and when they should be employed in the injury-repair cycle. Case management in the 
early stage must include a careful and detailed evaluation of the injury itself and define the most effective treatments to employ.

\section{Evaluating the outcome of rehabilitation and therapy}

Whether rehabilitation therapy takes the form of pharmacological manipulation of the CNS, behavioral modification techniques, or some combination of both, there must be detailed and comprehensive follow-up evaluations of functional outcomes. Carefully planned studies should be developed in collaboration with the various specialists involved in the therapeutic program. It will be necessary to compare distinct components of the treatments to determine which are most effective and which can be eliminated. Standards for measurement of clinical outcomes should be agreed upon by the rehabilitation community and applied in a manner that can demonstrate that the techniques do, in fact, improve functional outcome and that they meet the criteria for reliability (replicability) and validity (can be shown to make a difference).

The question of validating treatment methods is very much related to the issue of developing meaningful and consistently employed measures of functional recovery - issues that have yet to be resolved by rehabilitation specialists. Given the high costs of extended treatment for the brain-injured patient, it is unlikely that social agencies or companies providing payment for services will continue to do so unless they can be assured that a proposed professional medical/rehabilitation program is most likely to provide the optimum recovery available to the patient.

\section{When is it appropriate to begin treatment}

If we have learned anything about treating brain injury over these last years, it is that therapy to promote functional recovery must begin as soon as possible after the initial trauma. Delaying the course of treatment to observe how much "spontaneous recovery" is likely to occur, will, in most cases, result in treatment failure. Inflammatory reactions, edema, production of free radicals and excess excitatory amino acids, for example, must be eliminated before growth promoting and regenerating factors can have their effects. At the same time, psychological and social rehabilitation should begin as soon as the patient can tolerate this type of environmental stimulation.

\section{What is the appropriate course of therapy?}

There are many professionals who believe that unless recovery occurs within a relatively short time after injury, there will be no recovery at all. This is not the whole story. Optimum recovery is much more likely when treatment begins as early as possible after injury, but there is a substantial literature showing that recovery from aphasia and certain motor disorders can take years. Unless one is very fortunate, it is also the case that combinations of therapeutic agents will be needed, in both the early and later stages of injury, to treat the various syndromes that are produced by traumatic brain damage.

In the research laboratory, we examine single agents in order to determine what specific, physiological mechanisms are associated with the functional recovery. As different pharmacological agents are identified, it may be necessary to combine agents to produce maximum beneficial effects. Additionally, as more is learned about the continuum of changes that occur after an initial insult to the CNS, we will be better able to alter treatment to coincide with a "window of efficacy". These fields of research have yet to be adequately developed.

While it is true that a long course of medical and psychosocial therapy may be expensive, it may nonetheless be necessary if true functional recovery is the goal. Such therapy must be conducted in a positive, caring and enriched environment. Close cooperation and coordination of treatments among neurologists, physiatrists and rehabilitation psychologists should be the norm and the standard in the field of restorative neurology. Based upon what we know from experiments in laboratory animals $/ 25,26,31,64 /$, environmental enrichment, coupled with appropriate pharmacological treatments, may hold out the best hope for functional recovery in severely brain-injured patients, but only if one is prepared to invest the necessary time and effort to accomplish this goal.

In conclusion, there is no doubt that those concerned with basic research in restorative 
neuroscience have made great progress in opening new lines of inquiry and in developing a much better understanding of the injury and recovery process. Following the great strides in molecular biology, many research laboratories and pharmaceutical companies are beginning to identify or develop new agents capable of protecting the nervous system or facilitating recovery from brain injury. The selective use of such biochemical agents with respect to specific brain trauma and individual subject-related variables, in combination with behavioral and psychologically-oriented treatment methods, may ultimately lead to a system of comprehensive treatments tailored to various forms of brain injury.

\section{REFERENCES}

1. Attella MJ, Hoffman SW, Pilotte MP, STein DG Effects of BIM-22015, an anlog of $\mathrm{ACTH}_{4-10}$, on functional recovery after frontal cortex injury. Behav Neural Biol 1992; 57: 157-166.

2. Attella MJ, Hoffman SW, Stasio MJ, Stein DG. Ginkgo biloba extract facilitates recovery from penetrating brain injury in adult male rats. Exp Neurol 1989; 105: 62-71.

3. Attella MJ, Nattinville A, Stein DG. Hormonal state affects recovery from frontal cortex lesions in adult female rats. Behav Neural Biol 1987; 48: 352-367.

4. Auburger GR, Heumann R, Hellweg S, Korsching S; Thoenen $H$. Developmental changes of nerve growth factor and its mRNA in the rat hippocampus: Comparison with choline acetyltransferase. Dev Biol 1987; 120: 322-328.

5. Barde Y-A. Trophic factors and neuronal survival: Rev Neuron 1989; 2: 1525-1534.

6. Barres B.A. New roles for glia. J Neurosci 1991; 11 : 3685-3694.

7. Boast CA, Gerhardt SC, Pastor G, Lehmann J, Etienne PE, Liebman JM. The N-methyl-D-aspartate antagonists CGS 19744 and CPP reduce ischemic brain damage in gerbils. Brain Res 1988; 442: 345348.

8. Brailowsky S, Montiel T, Hernandez-Echeagaray E, Flores-Hernandez J, Hernandez-Pineda R. Effects of a Ginkgo biloba extract on two models of cortical hemiplegia in rats. Restorative Neurol Neurosci 1991; 3: 267-274.

9. Brauqet P, Esanu A, Buisine E, Hosford D, Broquet C, Koltai M. Recent progress in ginkgolide research. Med Res Rev 1991; 11: 295-355.

10. Bredsen DE, Hisanaga $K$, Sharp S-I. Neural transplantation using temperature-sensitive immortalized cells: A preliminary report. Ann Neurol 1990; 27: 205-207.

11. Bremer EG, Schlessinger J, Hakomori S-I Ganglioside-mediated modulation of cell growth. Specific effects of GM3 on tyrosine phosphorylation of the epidermal growth factor receptor. J Biol Chem 1986; 261: 2434-2440.

12. Butcher LL, Woolf NJ. Neurotrophic agents may exacerbate the pathologic cascade of Alzheimer's disease. Neurobiol Aging 1989; 10: 557-570.

13. Chen LS, Ray J, Fisher LJ, Kawaja MD, Schinstine M, Kang UJ, Gage FH. Cellular replacement therapy for neurologic disorders: Potential of genetically engineered cells. J Cell Biochem 1991; 45: 252-257.

14. Chollet F, DiPiero V, Wise RJS, Brooks DJ, Dolan RJ, Frackowiak RSJ. The functional anatomy of motor recovery after stroke in humans: A study with positron emission tomography. Ann Neurol 1991; 29: 63-71.

15. Clifton GL, Lyeth BG, Jenkins LW, Taft WC, DeLorenzo RJ, Hayes RL. Effect of D, alphatocopheryl succinate and polyethylene glycol on performance tests after fluid percussion brain injury. J Neurotrauma 1989; 6: 71-81.

16. Cooper JR, Bloom FE, Roth RH. The Biochemical Basis of Neuropharmacology. New York: Oxford University Press, 1986.

17. Cotman $\mathrm{CW}$, Nieto-Sampedro $M$. Progress in facilitating the recovery of function after cetral nervous system trauma. Ann NY Acad Sci 1985; 457: 83-104.

18. De Weid D. Inhibitory effects of ACTH and related peptides in extinction of conditioned avoidance behavior in rats. Proc Soc Exp Biol Med 1966; 122: 28-36.

19. Di Patre PL, Casamenti F, Cenni A, Pepeu G. Interaction between nerve growth factor and GM1 monosialoganglioside in preventing cortical choline acetyltransferase and high affinity choline uptake decrease after lesion of the nucleus basalis. Brain Res 1989; 480: 219-224.

20. Elliott PJ, Garofalo L, Cuello AC. Limited neocortical devascularizing lesions causing deficits in memory retention and chline acetyltransferase activity - effects of the monosialoganglioside GM1. Neuroscience 1989; 31: 63-76.

21. Faden AI, Demediuk P, Panter SS, Vink R. The role of excitatory amino acids and NMDA receptors in traumatic brain injury. Science 1989; 244: 799-800.

22. Fagan AM, Gage FH. Cholinergic sprouting in the hippocampus: A proposed role for IL-1. Exp Neurol 1990; 110: 105-120.

23. Fass B, Ramirez JJ. Effects of ganglioside treatments on lesion-induced behavioral impairments and sprouting in the CNS. J Neurosci Res 1984; 12: 445458.

24. Feeney DM, Sutton RL. Pharmacology for recovery of function after brain injury. Crit Rev Neurobiol 1987; 3 : 135-197. 
25. Finger S, Stein DG. Fast- versus slow-growing lesions and behavioral recovery. In: Brain Damage and Recovery: Research and Clinical Perspectives. Academic Press 1982; 153-173.

26. Finger S. Environmental attenuation of brain lesion symptoms. In: Finger S, ed, Recovery from Brain Damage: Research and Theory. New York: Plenum Press 1978.

27. Gage FH, Kawaja MD, Fisher LJ. Genetically modified cells: Applications for intracerebral grafting. TINS 1991; 14: 328-333.

28. Gage FH, Olejniczak P, Armstrong DM. Astrocytes are important for sprouting in the septohippocampal circuit. Exp Neurol 1988; 102: 2-13.

29. Goldman H, Morehead M, Hazlett J, Murphy S. An ACTH analog minimizes brain injury in a rat model. J Neurotrauma 1992; 9: 60.

30. Hefti F, Hartikka J, Knusel B. Function of neurotrophic factors in the adult and aging brain and their possible use in the treatment of neurodegenerative diseases. Neurobiol Aging 1989; 10: 515-533.

31. Held JM, Gordon J, Gentile AM. Environmental influences on locomotor recovery following cortical lesions in rats. Behav Neurosci 1985; 99: 678-690.

32. Kandel ER, Schwartz JH, Jessell TM. Principles of Neural Science (3rd ed.). New York: Elsevier 1991;

33. Karpiak SE, Mahadik SP, Wakade CG. Ganglioside reduction of ischemic injury. Crit Rev Neurobiol 1990; 5: 221-237.

34. Karpiak SE. Ganlioside tratment improves recovery of alternation behavior after unilateral entorhinal cortex lesion. Exp Neurol 1983; 81: 330-339.

35. Korsching $S$. The role of nerve growth factor in the CNS. TINS 1986; 9: 570-573.

36. Kromer L, Cornbrooks CJ. Identification of trophic factors and transplanted cellular environments that promote CNS axonal regeneration. Ann NY Acad Sci 1987; 495: 207-225.

37. Loy R, Milner TA. Sexual dimorphism in extent of axonal sprouting in rat hippocampus. Science 1990; 208: 1282-1284.

38. Martin DL. Synthesis and release of neuroactive substances by glial cells. Glia 1992; 5: 81-94.

39. McCall JM, Braughler JM, Hall ED. Lipid peroxidation and the role of oxygen radicals in CNS injury. Acta Anaesthesiol (Belgium) 1987; 38: 373379.

40. McIntosh RK, Vink R, Soares H, Hayes R, Simon R. Effect of non-competitive blockade of N-methyl-Daspartate receptors on the neurochemical sequelae of experimental brain injury. J Neurochem 1990; 55: 1170-1179.

41. Nieto-Sampedro M, Manthrope M, Barbin G, Varon S, Cotman CW. Injury-induced neuronotrophic activity in adult rat brain: Correlation with survival of delayed implants in the wound cavity. J Neurosci 1983; 3: 2219-2229.

42. Oberpichler H, Sauer, Rolfberg C, Mennel H-D. PAF antagonist ginkgolide $\mathrm{B}$ reduces postischemic neuronal damage in rat brain hippocampus. J Cere Blood Flow Metab 1990; 10: 133-135.

43. Olney JW. Neurotoxicity of excitatory amino acids. In: McGeer EG, Olney JW, McGeer PL, eds, Kainate as a Tool in Neurobiology. New York: Raven Press 1978; 95-121.

44. Phelps $\mathrm{CH}$, Gage FH, Growdon JH, Hefti F, Harbaugh R, Johnston MV, Khachaturian Z, Mobley W, Price D, Raskind M, Simpkins J, Thal L, Woodcodk J (Ad Hoc Working Group on Nerve Growth Factor and Alzheimer's Disease). Potential use of nerve growth factor to treat Alzheimer's disease. Science 1988; 243: 11.

45. Richter-Landsberg C, Bruns I, Flohr H. ACTH neuropeptides influence development and differentiation of embryonic rat cerebral cells in culture. Neurosci Res Comm 1987; 1: 153-162.

46. Rsenberg MB, Friedmann T, Robertson R, Tuszynski M, Wolff JA, Breakefield LO, Gage FH. Grafting genetically modified cells to the damaged brain: Restorative effects of NGF expression. Science 1988; 242: 1575-1578.

47. Sabel BA, DelMastro R, Dunbar GL, Stein DG. Reduction of anterograde degeneration in brain damaged rats by GM1-gangliosides. Neurosci Lett 1987; 77: 360-366.

48. Sabel BA, Slavin MD, Stein DG. GM1 ganglioside treatment facilitates behavioral recovery from bilateral brain damage. Science $1984 ; 225$ : 340-342.

49. Sabel BA, Dunbar GL, Stein DG. Gangliosides minimize behavioral deficits and enhance structural repair after brain injury. J Neurosci Res 1984; 12: 429 . 443.

50. Schallert T, Jones RA, Lindner MD. Multilevel transneuronal degeneration after brain damage: Behavioral events and effects of anticonvulsant gamma-aminobutyric acid-related drugs. Stroke 1990; 21 (Suppl. III): III 143-146.

51. Schallert T, Hernandez TD, Barth TM. Recovery of function after brain damage: Severe and chronic disruption by diazepam. Brain Res 1986; 379: 104111.

52. Schengrund $\mathrm{C}-\mathrm{L}$. The role(s) of gangliosides in neural differentiation and repair: A Perspective. Brain Res Bull 1990; 24: 131-141.

53. Schneider JS, Pope A, Simpson K, Taggart J, Smith MG, DiStefano L. Recovery from experimental parkinsonism in primates with GM1 ganglioside treatment. Science 1992; 256: 843-846.

54. Stein DG, Halks-Miller M, Hoffman SW. Intracerebral administration of alpha-tocopherol-containing liposomes facilitates behavioral recovery in rats with 
bilateral lesions of the frontal cortex. J Neurotrauma 1991; 8: 281-292.

55. Strand FL, Rose KJ, King JA, Segarra AC, Zuccarelli LA. ACTH modulation of nerve development and regeneration. Prog Neurobiol 1989; 33: 45-85.

56. Teichberg VI. Glial glutamate receptors: likely actors in brain signaling. FASEB J 1991; 5: 3086-3091.

57. Tyurin VA, Tyurina YY, Avrova NF. Gangliosidedependent factor, inhibiting lipid peroxidation in rat brain synaptomsomes. Neurochem Int 1992; 20: 401407.

58. Walsh TJ, Emerich DF, Schmechel DE. GM1 ganglioside attenuates the behavioral deficits but not the granule cell damage produced by intradenate colchicine. Brain Res 1989; 478: 24-33.

59. Wan Hua AY. Sex difference in the regeneration of the hypoglossal nerve. Brain Res 1982; 238: 404-406.

60. Warner MA, Neill KH, Nadler JV, Crain BJ. Regionally selective effects of NMDA receptor antagonists against ischemic brain damage in the gerbil. J Cereb Blood Flow Metab 1991; 11: 600-610.

61. Weihmuller FB, Hadjiconstantinou M, Bruno JP, Neff $\mathrm{NH}$. Administration of GM1 ganglioside eliminates neuroleptic-induced sensorimotor deficits in MPTPtreated mice. Neurosci Lett 1988; 92: 207-212.

62. Weiller C, Chollet F, Friston KJ, Wise RJS, Frackowiak RSJ. Functional reorganization of the brain in recovery from striatocapsular infarction in man. Ann Neurol 1992; 31: 463-472.

63. Whitaker-Azmitia PM, Ramirez A, Noreika L, Gannon PJ, Azmitia EC. Onset and duration of astrocytic response to cells transplanted into the adult mammalian brain. Ann NY Acad Sci 1987; 495: 1023.

64. Will BE, Rosenzweig MR, Bennett EL, Hebert M, Morimoto H. Relatively brief environmental enrichment aids recovery of learning capacity and alters brain measures after postweaning brain lesions in rats. J Comp Physiol Psychol 1977; 91: 33-50.

65. Wolterink G, Van Zanten E, Kamsteeg H, Radhakishun FS, Van Ree JM. Functional recovery after destruction of dopamine systems in the nucleus accumbens of rats. III. Further analysis of the facilitating effect of the $\mathrm{ACTH}_{4-9}$ analog ORG 2766 . Brain Res 1990; 507: 109-114.

67. Zivin JA, Choi DW. Stroke therapy. Sci Am (July) 1991; 265: 56-63. 

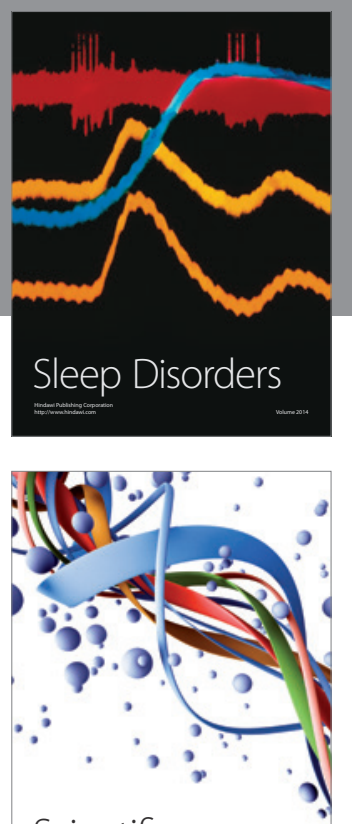

Scientifica
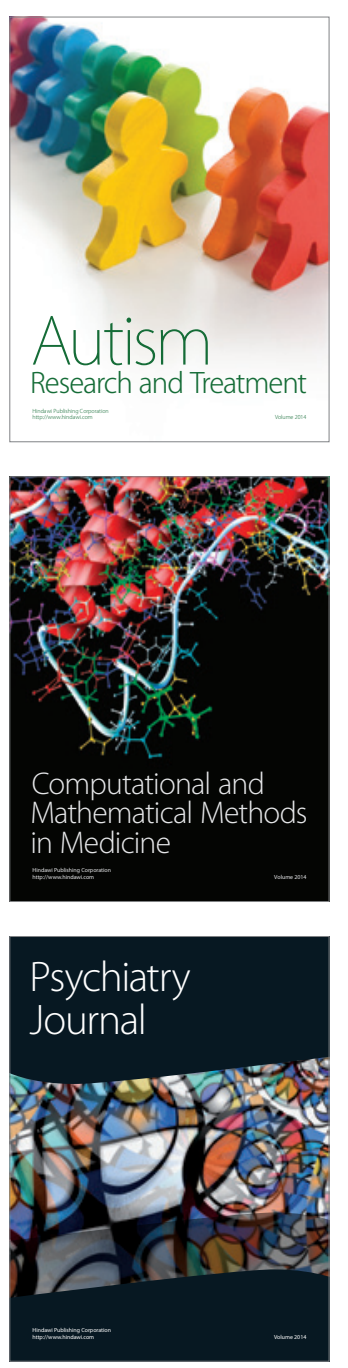
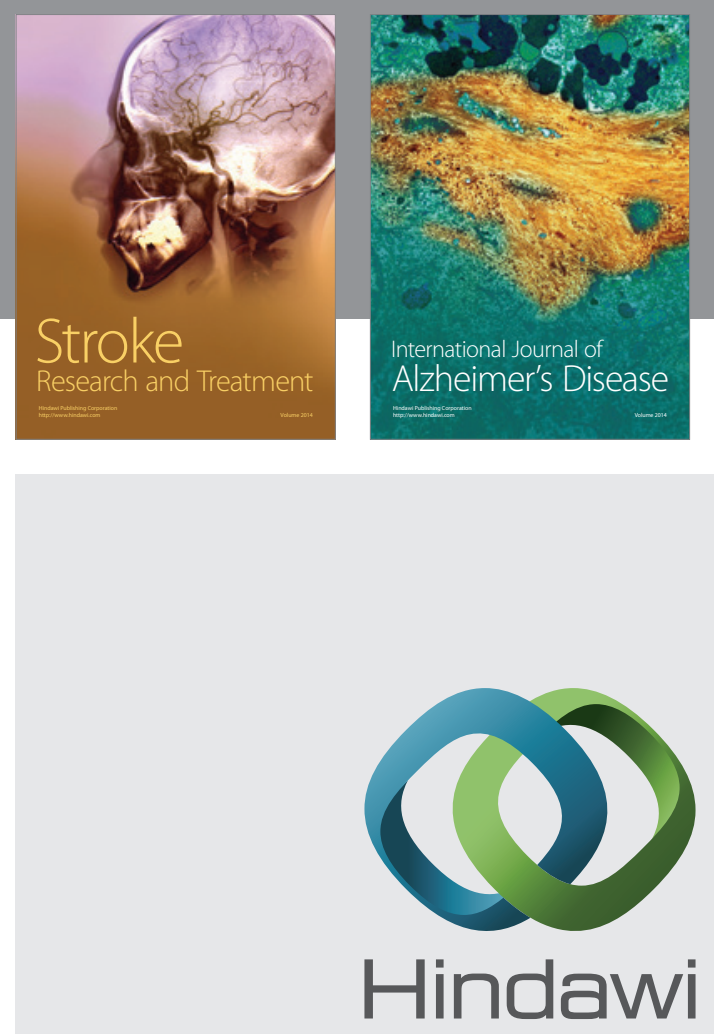

Submit your manuscripts at

http://www.hindawi.com
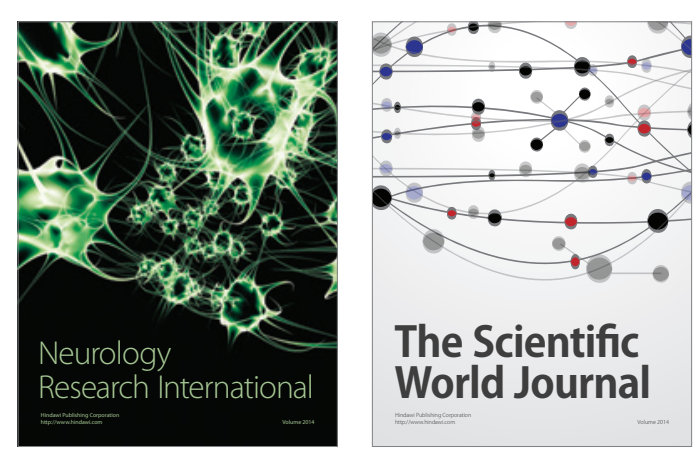

The Scientific World Journal

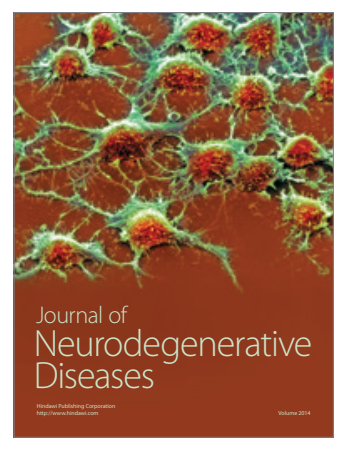

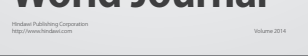

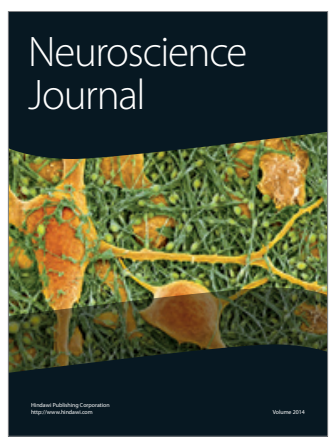

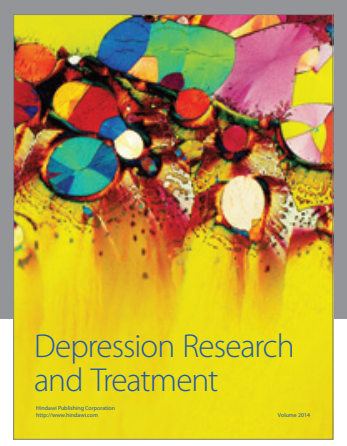
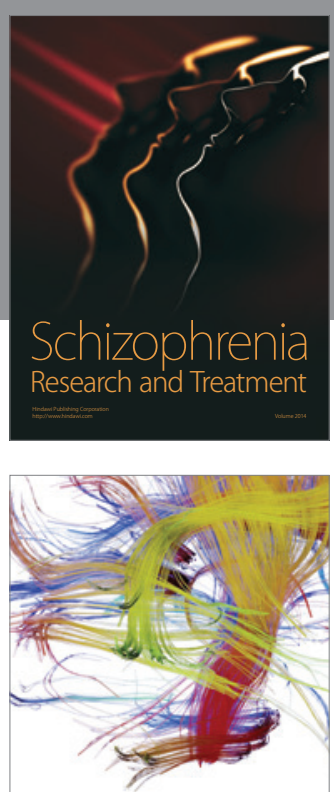

Brain Science

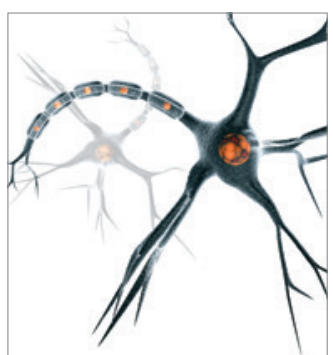

Neural Plasticity
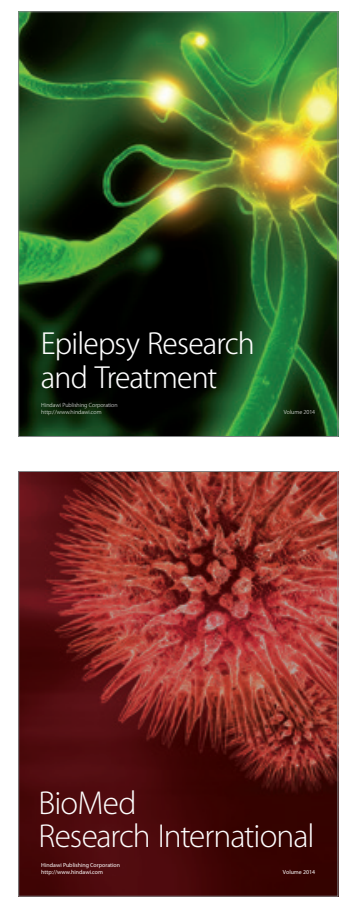

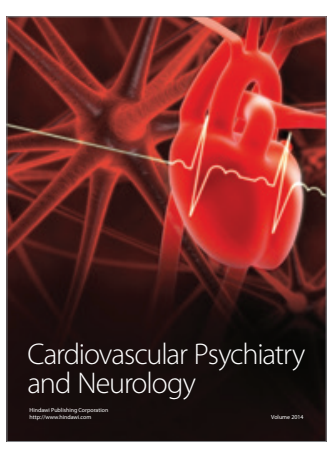

Parkinson's

Disease
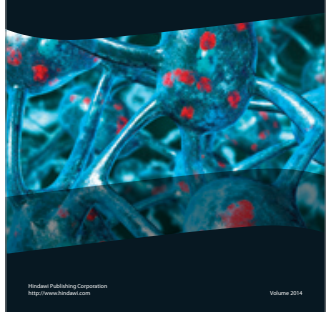